\title{
A novel nonsense mutation, E150X, in the SOX9 gene underlying campomelic dysplasia
}

\author{
Vorasuk Shotelersuk ${ }^{1}$, Somchit Jaruratanasirikul ${ }^{2}$, Thivaratana Sinthuwiwat ${ }^{1}$ and Waricha Janjindamai ${ }^{2}$ \\ ${ }^{1}$ Department of Pediatrics, Faculty of Medicine, Chulalongkorn University, Bangkok, Thailand. \\ ${ }^{2}$ Department of Pediatrics, Faculty of Medicine, Prince of Songkla University, Hatyai, Songkhla, Thailand.
}

\begin{abstract}
Campomelic dysplasia (CD) is an autosomal dominant skeletal malformation syndrome with features including bowed lower limbs with pretibial skin dimpling, hypoplastic scapulae and pelvic bones, and 11 pairs of ribs. Mutations in the SOX9 gene have been identified to cause CD. The gene encodes a transcription factor containing a dimerization, a high mobility group, and a C-terminal transactivation (TA) domain. Up to now, 35 SOX9 mutations have been published. In the present study, we describe a Thai girl with clinically and radiologically typical CD. Direct sequencing analysis of the PCR products for the entire coding region of SOX9 revealed that she was heterozygous for a novel 448G > T in exon 2 of SOX9. The DNA change was expected to result in E150X and loss of the entire TA domain. This result further supports that SOX9 is the only gene, discovered to date, responsible for CD across different populations and that the TA domain is important to the function of the normal SOX9.
\end{abstract}

Key words: $\mathrm{SOX} 9$, campomelic dysplasia, mutation.

Received: July 14, 2006; Accepted: July 25, 2006.

Campomelic dysplasia (CD, MIM 114290) is an autosomal dominant skeletal malformation syndrome characterized by the radiological features of bowing of femora and tibiae, hypoplastic scapulae and pelvic bones, 11 pairs of ribs, and non-mineralized thoracic pedicles. Clinically, an affected infant manifests bowed lower limbs with pretibial skin dimpling, Robin sequence, a flat nasal bridge, low set ears, bilateral clubfoot and congenital dislocation of the hips. Three-quarters of karyotypically normal males with $\mathrm{CD}$ show various levels of male-to-female sexual differentiation. The majority of patients die in the neonatal period because of respiratory distress (Mansour et al., 1995).

The SOX9 gene on chromosome region 17q24.3-25.1 was isolated and mutations identified as being responsible for CD (Foster et al., 1994; Wagner et al., 1994). The gene encodes a transcription factor containing a homolog of the SRY high mobility group (HMG) domain, a C-terminal transactivation (TA) domain (Sudbeck et al., 1996; McDowall et al., 1999), and a recently identified dimerization domain (Bernard et al., 2003; Sock et al., 2003). In accordance with the CD phenotype, SOXO is expressed throughout chondrogenesis (Bi et al., 1999) and in the geni-

Send correspondence to Vorasuk Shotelersuk. Head of Division of Medical Genetics and Metabolism, Department of Pediatrics, Sor Kor Building $11^{\text {th }}$ floor, King Chulalongkorn Memorial Hospital, Bangkok 10330, Thailand. E-mail: vorasuk.s@chula.ac.th. tal ridges of both sexes (Morais da Silva et al., 1996; Vidal et al., 2001).

Up to now, 35 SOX9 mutations have been published (Foster et al., 1994; Wagner et al., 1994; Kwok et al., 1995; Cameron et al., 1996; Meyer et al., 1997; Goji et al., 1998; McDowall et al., 1999; Olney et al., 1999; Pfeifer et al., 1999; Ninomiya et al., 2000; Thong et al., 2000; Giordano et al., 2001; Sock et al., 2003; Pop et al., 2004; Pop et al., 2005). They occur across the entire open reading frame and include missense, nonsense, frameshift, and splice mutations. Most of these mutations were heterozygous and appeared to cause loss of function of SOX9. CD, therefore, can be regarded as a haploinsufficiency syndrome. However, there is no apparent genotype/phenotype correlation concerning mutation type or position and severity of the disease and associated sex reversal, pointing to variable expressivity of the disease (Meyer et al., 1997).

In the present study, we describe a Thai patient with $\mathrm{CD}$ who was found to be heterozygous for a novel nonsense mutation. The patient was born after uncomplicated pregnancy at 38 weeks gestation by caesarean section due to breech presentation to a 28-year-old, gravida 2, para 1 Thai mother and a 32-year-old unrelated Thai father. Birth weight was $2,770 \mathrm{~g}$ and length $40 \mathrm{~cm}$. Physical examination at birth revealed macrocephaly with a head circumference of $38.5 \mathrm{~cm}$, a wide anterior fontanelle of $4 \times 4 \mathrm{~cm}$, a poste- 
rior fontanelle of $1 \times 1 \mathrm{~cm}$, flat nasal bridge, long philtrum, low set ears, micrognathia, short neck, and short sternum. Cardiothoracic examination revealed no cardiac murmur, and normal breath sound. She had short bowed legs with pretibial skin dimpling bilaterally (Figure 1). Genitalia were of normal female. No mass was palpable in the inguinal area. Her parents and elder sibling were unaffected.

After birth, the girl developed respiratory distress with intercostal retraction. A chest X-ray demonstrated small thoracic cage, small scapulae, and 11 pairs of ribs (Figure 2A). Skeletal survey revealed small iliac wings, mild bowing of femora and tibiae bilaterally (Figure 2B). Brain ultrasonography showed dilated ventricles consistent with mild hydrocephalus. Chromosomal study revealed a normal karyotype of 46,XX. The girl was intubated with ventilatory support. After 3 episodes of ventilatorassociated pneumonia, she developed sepsis and expired at the age of 67 days.

After informed consent, peripheral blood $(3 \mathrm{~mL})$ was obtained from the girl and DNA extracted by standard methods. Blood samples from her parents were unavailable. The three exons of the $S O X 9$ gene, containing the entire coding region, were PCR-amplified from genomic DNA using primers and conditions shown in Table 1 (Exon 1 was amplified using primers Ex1-F and Ex1-R, exon 2 us-

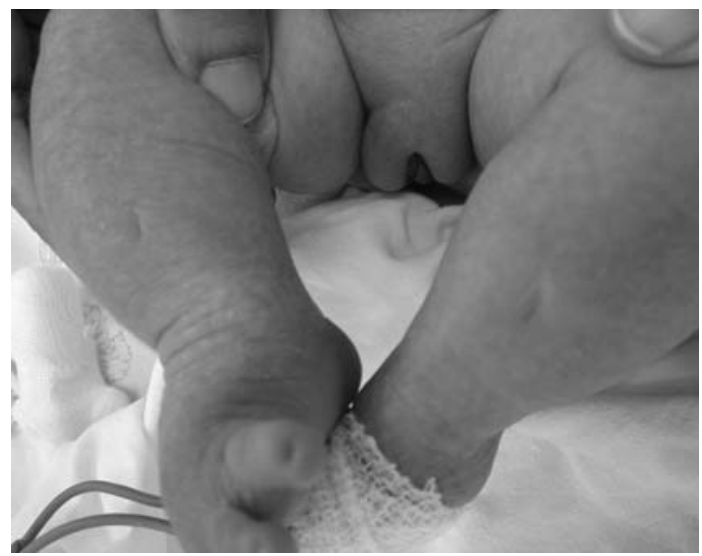

Figure 1 - The patient has short bowed legs with bilateral pretibial skin dimpling.

ing primers Ex2-F and Ex2-R, and exon 3 using nested primers Ex3-F1 and Ex3-R1 followed by Ex3-F2 and Ex3R2). We used $3 \mu \mathrm{L}$ of DNA, 1X PCR buffer (Fermentas, Burlington, Ontario, Canada), $1.5 \mathrm{mM} \mathrm{MgCl}_{2}, 0.2 \mathrm{mM}$ dNTPs, $0.2 \mu \mathrm{M}$ of each primer, and $0.025 \mathrm{U}$ Taq DNA polymerase (Fermentas, Burlington, Ontario, Canada) in a total volume of $20 \mu \mathrm{L}$. The PCR products were treated with ExoSAP-IT (USP Corporation, Cleveland, Ohio; a mixture of exonuclease to eliminate residual oligonucleotide primers and shrimp alkali phosphatase to degrade dNTPs into deoxynucleotides) according to the company recommendations, and sent for direct sequencing at the Macrogen Inc., Seoul, Korea.

Direct sequencing analysis of the PCR products revealed that the girl was heterozygous for $G>T$ point mutation at nucleotide position 448 [448G $>$ T] in exon 2 of SOX9 (Figure 3). The DNA change was expected to result in a change of glutamic acid (GAG) at codon 150 to a stop codon (TAG) [E150X]. No other sequence variants for the remainder of the $S O X 9$ gene were found.

We describe a clinically and radiologically typical CD Thai girl. Our patient had bilateral bowed lower limbs with pretibial skin dimpling, micrognathia, a flat nasal bridge, and low set ears with radiological findings of bilateral bowing of femora and tibiae, hypoplastic scapulae and pelvic bones, and 11 pairs of ribs. Her genitalia of a normal female corresponded to her karyotype of normal 46,XX.

A

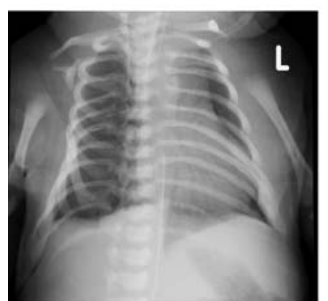

$\mathrm{B}$

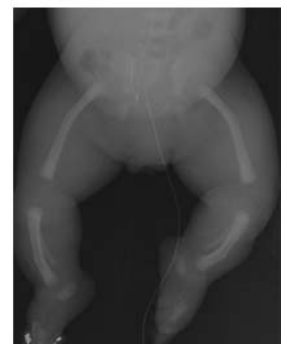

Figure 2 - X-rays showing (A) small thoracic cage, small scapulae, 11 pairs of ribs, (B) small iliac wings and mild bowing of femora and tibiae bilaterally.

Table 1 - Oligonucleotides and PCR conditions for $S O X 9$ mutation analysis.

\begin{tabular}{llcc}
\hline Name & Primer sequences for PCR 5' to 3' & $\begin{array}{c}\text { Product size } \\
\text { (bp) }\end{array}$ & $\begin{array}{c}\text { Annealing } \\
\text { temperature }\left({ }^{\circ} \mathrm{C}\right)\end{array}$ \\
\hline Ex1-F & CGC CTT CCT AAG TGC TCG CC & 765 & 65 \\
Ex1-R & ACT CTG AGC CAC AGT TAC AC & & 63 \\
Ex2-F & TGT GCA GAG GAA GCC GAG TG & 455 & 62 \\
Ex2-R & AAG AAT CTC CCA GGC GGA GG & & 6 \\
Ex3-F1 & CCC GGA GGG TGC CTA AGA CTA & 1,099 & 62 \\
Ex3-R1 & GCT AAA GGC AAC TCG TAC CC & & \\
Ex3-F2 & TGT GGA TGT CCA AGC AGC AG & 573 \\
Ex3-R2 & GAT GTG CGT TCG CTG GGA CTG & & \\
\hline
\end{tabular}




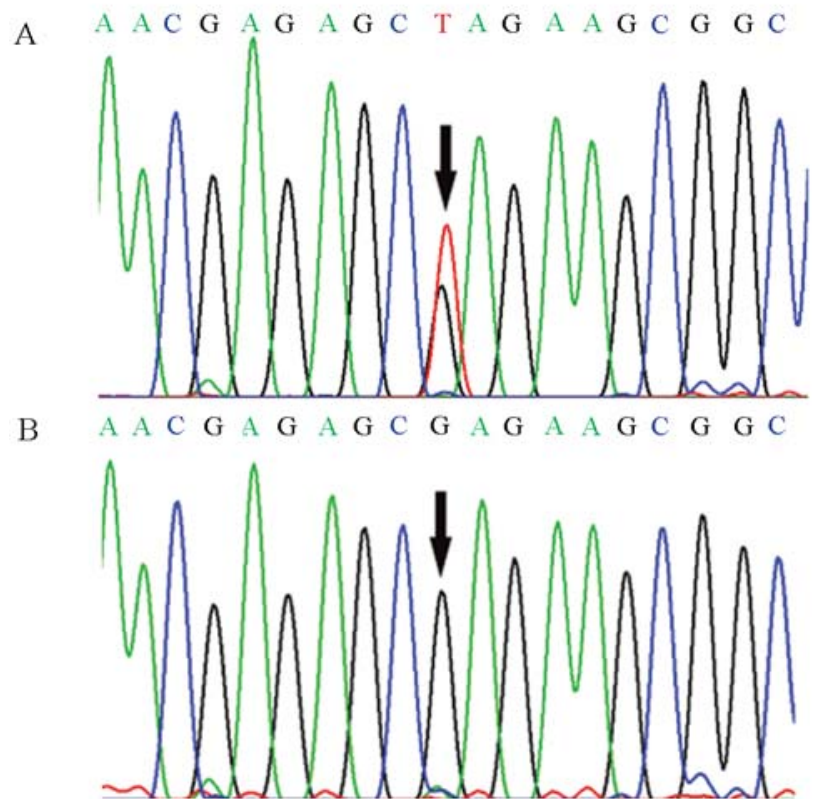

Figure 3 - Mutation analysis. The sense sequence electropherogram of the SOX9 exon 2 from (A) the patient and (B) control. The proband shows a heterozygous $\mathrm{G}>\mathrm{T}$ mutation converting a glutamic acid residue (GAG) to a stop codon (TAG), designated as E150X.

She was, therefore, uninformative regarding genital discrepancies in patients with $\mathrm{SOX} 9$ mutations. Despite intensive treatment, the patient expired at the age of 67 days, consistent with the typical natural history of most patients with CD (Mansour et al., 1995).

A heterozygous $448 \mathrm{G}>\mathrm{T}$ point mutation in exon 2 of SOX9 was identified in our patient. The gene encodes a transcription factor containing a dimerization domain immediately preceding the HMG domain (Bernard et al., 2003; Sock et al., 2003), a HMG domain (codons 101-184), and a C-terminal TA domain (codons 339-379) (Sudbeck et al., 1996; McDowall et al., 1999). At least 35 SOX9 mutations have been identified (Foster et al., 1994; Wagner et al., 1994; Kwok et al., 1995; Cameron et al., 1996; Meyer et al., 1997; Goji et al., 1998; McDowall et al., 1999; Olney et al., 1999; Pfeifer et al., 1999; Ninomiya et al., 2000; Thong et al., 2000; Giordano et al., 2001; Sock et al., 2003; Pop et al., 2004; Pop et al., 2005). The most frequent recurrent mutation in SOX9 is Y440X (Pop et al., 2005). Although a homozygous mutation due to a mitotic gene conversion has been identified in a patient with CD (Pop et al., 2005), most of the mutations identified in CD patients were heterozygous and appeared to cause loss of function of $S O X$, probably due to haploinsufficiency. However, there is no apparent genotype/phenotype correlation (Meyer et al., 1997). The E150X point mutation found in our patient, which has not been previously reported, would be expected to result in a truncated protein with 149 amino acids and loss of a part of HMG domain and the entire TA domain. The mutation could cause $\mathrm{CD}$ by haploinsufficiency. Another possibility is that the mutant trun- cated protein with the intact dimerization domain could bind the wide type protein and act in a dominant negative manner. These possibilities of the effect of the mutation need further investigations. Nonetheless, this observation supports the hypothesis that the TA domain is important to the function of the normal SOX9, and SOXY is the only gene, discovered to date, responsible for $\mathrm{CD}$ across different populations. In addition, the findings give the family more options. We could perform molecular prenatal diagnosis for future pregnancies of this couple. Even though recurrence is low, there have been reports of familial occurrence suggesting gonadal mosaicism (Cameron et al., 1996).

In summary, we describe a CD Thai girl with a novel nonsense mutation expected to result in a loss of TA domain of $S O X 9$. This result further supports that $S O X 9$ is the only gene, discovered to date, responsible for CD across different populations and that the TA domain is important to the function of the normal SOX9.

\section{Acknowledgment}

This study was supported by the Research Unit Grant from Chulalongkorn University, the National Center for Genetic Engineering and Biotechnology, and the Thailand Research Fund.

\section{References}

Bernard P, Tang P, Liu S, Dewing P, Harley VR and Vilain E (2003) Dimerization of SOX9 is required for chondrogenesis, but not for sex determination. Hum Mol Genet 12:1755-1765.

Bi W, Deng JM, Zhang Z, Behringer RR and de Crombrugghe B (1999) Sox9 is required for cartilage formation. Nat Genet 22:85-89.

Cameron FJ, Hageman RM, Cooke-Yarborough C, Kwok C, Goodwin LL, Sillence DO and Sinclair AH (1996) A novel germ line mutation in $S O X 9$ causes familial campomelic dysplasia and sex reversal. Hum Mol Genet 5:1625-1630.

Foster JW, Dominguez-Steglich MA, Guioli S, Kowk G, Weller PA, Stevanovic M, Weissenbach J, Mansour S, Young ID, Goodfellow PN, Brook JD and Schafer AJ. (1994) Campomelic dysplasia and autosomal sex reversal caused by mutations in an SRY-related gene. Nature 372:525-530.

Giordano J, Prior HM, Bamforth JS and Walter MA (2001) Genetic study of $S O X 9$ in a case of campomelic dysplasia. Am J Med Genet 98:176-181.

Goji K, Nishijima E, Tsugawa C, Nishio H, Pokharel RK and Matsuo M (1998) Novel missense mutation in the HMG box of $S O X 9$ gene in a Japanese XY male resulted in campomelic dysplasia and severe defect in masculinization. Hum Mutat Suppl 1:S114-116.

Kwok C, Weller PA, Guioli S, Foster JW, Mansour S, Zuffardi O, Punnett HH, Dominguez-Steglich MA, Brook JD, Young ID, Goodfellow PN and Schafer AJ (1995) Mutations in SOX9, the gene responsible for Campomelic dysplasia and autosomal sex reversal. Am J Hum Genet 57:1028-1036. 
Mansour S, Hall CM, Pembrey ME and Young ID (1995) A clinical and genetic study of campomelic dysplasia. J Med Genet 32:415-420.

McDowall S, Argentaro A, Ranganathan S, Weller P, Mertin S, Mansour S, Tolmie J and Harley V (1999) Functional and structural studies of wild type $S O X 9$ and mutations causing campomelic dysplasia. J Biol Chem 274:24023-24030.

Meyer J, Sudbeck P, Held M, Wagner T, Schmitz ML, Bricarelli FD, Eggermont E, Friedrich U, Haas OA, Kobelt A, Leroy JG, Van Maldergem L, Michel E, Mitulla B, Pfeiffer RA, Schinzel A, Schmidt H and Scherer G (1997) Mutational analysis of the SOXY gene in campomelic dysplasia and autosomal sex reversal: Lack of genotype/phenotype correlations. Hum Mol Genet 6:91-98.

Morais da Silva S, Hacker A, Harley V, Goodfellow P, Swain A and Lovell-Badge R (1996) Sox 9 expression during gonadal development implies a conserved role for the gene in testis differentiation in mammals and birds. Nat Genet 14:62-68.

Ninomiya S, Yokoyama Y, Teraoka M, Mori R, Inoue C, Yamashita S, Tamai H, Funato M and Seino Y (2000) A novel mutation $(296$ del G) of the $S O X 9$ gene in a patient with campomelic syndrome and sex reversal. Clin Genet 58:224-227.

Olney PN, Kean LS, Graham D, Elsas LJ and May KM (1999) Campomelic syndrome and deletion of SOX9. Am J Med Genet 84:20-24.

Pfeifer D, Kist R, Dewar K, Devon K, Lander ES, Birren B, Korniszewski L, Back E and Scherer G (1999) Campomelic dysplasia translocation breakpoints are scattered over $1 \mathrm{Mb}$ proximal to $S O X 9$ : Evidence for an extended control region. Am J Hum Genet 65:111-124.

Pop R, Conz C, Lindenberg KS, Blesson S, Schmalenberger B, Briault S, Pfeifer D and Scherer G (2004) Screening of the 1 Mb SOX9 5' control region by array CGH identifies a large deletion in a case of campomelic dysplasia with XY sex reversal. J Med Genet 41:e47.

Pop R, Zaragoza MV, Gaudette M, Dohrmann U and Scherer G (2005) A homozygous nonsense mutation in SOXY in the dominant disorder campomelic dysplasia: A case of mitotic gene conversion. Hum Genet 117:43-53.

Sock E, Pagon RA, Keymolen K, Lissens W, Wegner M and Scherer G (2003) Loss of DNA-dependent dimerization of the transcription factor $S O X 9$ as a cause for campomelic dysplasia. Hum Mol Genet 12:1439-1447.

Sudbeck P, Schmitz ML, Baeuerle PA and Scherer G (1996) Sex reversal by loss of the $\mathrm{C}$-terminal transactivation domain of human SOX9. Nat Genet 13:230-232.

Thong MK, Scherer G, Kozlowski K, Haan E and Morris L (2000) Acampomelic campomelic dysplasia with $S O X 9$ mutation. Am J Med Genet 93:421-425.

Vidal VP, Chaboissier MC, de Rooij DG and Schedl A (2001) Sox9 induces testis development in XX transgenic mice. Nat Genet 28:216-217.

Wagner T, Wirth J, Meyer J, Zabel B, Held M, Zimmer J, Pasantes J, Bricarelli FD, Keutel J, Hustert E, Wolf U, Tommerup N, Schempp W and Scherer G (1994) Autosomal sex reversal and campomelic dysplasia are caused by mutations in and around the SRY-related gene SOX9. Cell 79:1111-1120.

Associate Editor: Peter L. Pearson 